\title{
Expert Views on Effectiveness, Feasibility, and Implementation of Biosecurity Measures for Mitigating Tier 1 Disease Risks in the U.S. Swine, Beef Cattle, and Dairy Industries
}

\author{
Qianrong Wu${ }^{1}$, Lee L Schulz ${ }^{1 *}$, Glynn T Tonsor ${ }^{2}$ and Julia M Smith ${ }^{3}$ \\ ${ }^{1}$ Department of Economics, lowa State University, Ames, lowa, USA \\ ${ }^{2}$ Department of Agricultural Economics, Kansas State University, Manhattan, Kansas, USA \\ ${ }^{3}$ Department of Animal and Veterinary Sciences, The University of Vermont, Burlington, Vermont, USA
}

\begin{abstract}
Understanding disease transmission routes and implications for biosecurity is critical to mitigating livestock disease outbreaks and maintaining efficient and profitable production. The goal of biosecurity is to eliminate pathogen exposure and minimize endemic pathogen impact, particularly important for foreign animal diseases that threaten U.S. animal health and the economy. We elicit swine, beef cattle, and dairy expert views on the effectiveness, feasibility, and implementation of both biosecurity measures targeting disease transmission routes and specific biosecurity measures. Biosecurity targeting direct animal-to-animal contact, semen, people, and vehicles and other fomites was identified as the most effective and feasible for the swine, beef cattle, and dairy industries. Efforts targeting airborne and arthropod transmission were ranked low for effectiveness and feasibility across all three industries. The swine industry had higher estimated implementation of biosecurity against most disease transmission routes. All-in and all-out production had the highest estimated implementation in the swine industry. In the beef cattle industry, performing daily observations by producer/employees had the highest estimated implementation. Reduced environmental viral load through pathogen reduction had the lowest estimated implementation in the swine and beef cattle industries. In the dairy industry, monitoring production records for health status changes had the highest estimated implementation, and line of separation in place for all employees entering premises had the lowest. Swine experts considered separation line for all animals entering/leaving premises and reduced environmental viral load through pathogen reduction the most and least effective and feasible, respectively. Stabilization and monitoring for affected premises and daily observations by producer/employees were identified as most effective and feasible by beef cattle and dairy experts, respectively. All-in and all-out production was rated least effective and feasible by both beef cattle and dairy experts.
\end{abstract}

Keywords: Beef cattle; Biosecurity; Dairy; Expert survey; Foreign animal disease; Swine

\section{Introduction}

State and federal animal health officials must be prepared to help deal with new, emerging, and foreign animal diseases characterized by uncertainty and complexity. Understanding disease transmission risks in light of current implementation of mitigating strategies can help identify opportunities for disease prevention and outbreak containment. In the event of a large, rapidly spreading foreign animal disease outbreak, biosecurity is the only tool realistically available as a means of control [1].

In this study we define biosecurity as "the implementation of measures that reduce the risk of disease agents being introduced and spread where biosecurity measures should be used to avoid the entry of pathogens into a herd or farm (external biosecurity) and to prevent the spread of disease to uninfected animals within a herd or to other farms, when the pathogen is already present (internal biosecurity)." [2].

Although biosecurity recommendations are often based on the risk of introduction of endemic diseases [3], there is always the risk of a new, emerging disease entering the United States that may circumvent current biosecurity recommendations [4,5]. An analysis of data from the National Animal Health Monitoring System (NAHMS) indicates $32.1 \%$ of beef cow-calf operations disagreed or strongly disagreed with the statement, "The United States is well prepared to handle outbreaks of livestock disease currently not found in this country, such as footand-mouth disease and rinderpest." [6].
Understanding the drivers of behavior is crucial to developing effective strategies that result in behavior changes [7] and greater protection against new, emerging, or foreign diseases or pests. Social science approaches are being employed to better understand the mindset of producers and influential professionals about biosecurity [811]. The literature includes a few assessments of expert views on factors influencing biosecurity decisions. Nissen and Krieter [12] compared risk factors in terms of importance for the introduction and spread of classical swine fever and foot-and-mouth disease in Germany. Kuster et al. [13] assessed the effectiveness and importance of individual on-farm biosecurity measures for preventing a host of infectious agents from entering and spreading on cattle and swine farms in Switzerland.

Given the size, structure, and extensive movement inherent in the U.S. livestock industry, which presents unprecedented challenges in the

*Corresponding author: Lee L Schulz, Assistant Professor, Department of Economics, lowa State University, 478D Heady Hall, 518 Farm House Lane, Ames, IA, 50011-1054, USA, Tel: +15152943356; E-mail: Ischulz@iastate.edu

Received March 20, 2017; Accepted March 28, 2017; Published March 30, 2017

Citation: Wu Q, Schulz LL, Tonsor GT, Smith JM (2017) Expert Views on Effectiveness, Feasibility, and Implementation of Biosecurity Measures for Mitigating Tier 1 Disease Risks in the U.S. Swine, Beef Cattle, and Dairy Industries. J Vet Sci Technol 8: 435. doi: 10.4172/2157-7579.1000435

Copyright: (c) 2017 Wu Q, et al. This is an open-access article distributed unde the terms of the Creative Commons Attribution License, which permits unrestricted use, distribution, and reproduction in any medium, provided the original author and source are credited. 
Citation: Wu Q, Schulz LL, Tonsor GT, Smith JM (2017) Expert Views on Effectiveness, Feasibility, and Implementation of Biosecurity Measures for Mitigating Tier 1 Disease Risks in the U.S. Swine, Beef Cattle, and Dairy Industries. J Vet Sci Technol 8:1735. doi: 7579.1000435

event of foreign animal disease outbreak [14], additional research is needed with respect to implementation of biosecurity measures. For example, no country with a livestock industry comparable to that of the United States has had to deal with an outbreak of foot-and-mouth disease [1].

As important as understanding the risk factors for the introduction and spread of disease is understanding the drivers of behavior to mitigate these risks [15]. Implementation of measures to protect animal health comes with a cost that must be weighed against potential effectiveness (and necessity). Feasibility and effectiveness are mentioned in most discussions of biosecurity at the producer level [16], thus we chose to focus on perceived effectiveness and feasibility in our study.

Stakeholders in the livestock industry are regarded as key players in the communication, selection, and implementation of biosecurity measures. Hernández-Jover et al. [17] found that successful livestock disease risk reduction depends on trust and co-management among stakeholders. We targeted livestock industry experts such as veterinarians, epidemiologists, animal scientists, and economists for an initial survey exploring the effectiveness, feasibility, and implementation of biosecurity measures in the swine, beef cattle, and dairy industries.

Our focus was to evaluate biosecurity practices currently recommended against endemic diseases for their role in protecting against new, emerging, and foreign diseases. The specific objectives were two-fold: firstly, to identify expert views on the effectiveness (extent of risk reduction), feasibility (practicality of affordable implementation), and current implementation (adoption) of biosecurity measures applicable to specific disease transmission risks (termed routes in this paper); and secondly, to identify expert views on the effectiveness, feasibility, and implementation of a set of specific biosecurity measures.

\section{Materials and Methods}

\section{Questionnaire design and survey procedure}

The survey procedures were approved by the Kansas State University Committee for Research Involving Human Subjects (\#8132.1).

Three similar surveys were designed and circulated to swine, beef cattle, and dairy industry experts. Survey software, Qualtrics (Qualtrics, Provo, UT), was used to develop the surveys. Disease transmission routes and biosecurity measures were identified from the literature $[2,18]$. Nine disease transmission routes were examined: (1) direct animal-to-animal contact; (2) semen; (3) airborne transmission; (4) people; (5) vehicles and other fomites; (6) feed and drinking-water; (7) manure and bedding; (8) birds, bats, rodents, feral and wild livestock, and stray/domestic animals (hereafter referred to as wild carrying agents); and (9) arthropods. Nineteen biosecurity measures were examined (Tables 4, 5 and 6). All questionnaires included questions on all nine disease transmission routes. However, to minimize the risk of survey fatigue, questions on only five randomly selected biosecurity measures were presented to each respondent. To minimize the effect of order bias, items within each question were presented in random order. Demographic questions were also included to better identify the characteristics of the survey respondents.

To encourage the respondents to think in the context of disease risks that pose the most significant threat to U.S. agriculture as they have the highest risks and consequences, we defined and deliberately asked them to keep Tier 1 disease risks in mind when answering questions. Tier 1 diseases include African swine fever, classical swine fever, foot-and-mouth disease, avian influenza, and virulent Newcastle disease [19].

The surveys were distributed by the National Institute for Animal Agriculture (NIAA) and the American Association of Swine Veterinarians (AASV). This sampling method relied on these two organizations to distribute the surveys to their members or subscribers using their preferred means of communication. Modes of recruitment were email list serves for NIAA members and online newsletters for AASV members. These communications included a link to the survey website and text describing the study. A reminder message was sent three weeks after the initial recruitment notice. One of the authors attended the 2016 National Institute for Animal Agriculture Annual Meeting during the study period to describe the study and encourage participation.

In March and April of 2016, communication of the survey was circulated to 778 NIAA members (226 registered for the 2016 NIAA Annual Conference and 552 past members) and 1,965 AASV members (1,350 U.S. members, 285 international members, and 330 student members). These NIAA and AASV members were asked to complete the survey best aligned with the industry they were most familiar and engaged with-swine, beef cattle, or dairy. Respondents were also welcome to complete a survey for more than one industry.

\section{Statistical analysis}

Data from the survey software were exported and analyzed in Excel (Microsoft, Redmond, WA) and STATA [20]. As commonly used for the analysis of this type of data [21-23], cross-tabulations were used to compare responses by effectiveness, feasibility, and implementation. For example, of interest is whether biosecurity measures targeting a specific disease transmission route are both highly effective and highly feasible or highly ineffective and highly infeasible or some combination of the extreme ratings. Similar assessments were performed for specific biosecurity measures.

\section{Results}

\section{Response rate and respondent profile}

Of the possible 2,743 experts contacted to complete the survey(s), 190 completed questionnaires -55 experts from the swine industry, 70 experts from the beef cattle industry, and 65 experts from the dairy industry $(6.93 \%$ effective response rate). However, several surveys were only partially completed. For the analysis, 33, 38, and 37 surveys completed by swine experts, beef cattle experts, and dairy experts, respectively, were used. Descriptive statistics of the demographics (i.e., discipline, employment, and biosecurity expertise) of respondents are shown in Table 1.

Type of operation familiar to experts varied by species. Eighty-four percent of dairy experts most commonly interact with commercial operations and the rest of them with non-commercial operations. The beef cattle experts most commonly interact with cow-calf (79\%), stocker (3\%), feedlot (11\%), and other operations (8\%). Swine experts most commonly interact with farrow-finish (36\%), farrow-wean (27\%), feeder-finish (3\%), wean-finish (9\%), and other operations (24\%).

Respondents interacted with operations in states with the largest number of operations and largest livestock populations. Approximately one-third of the swine experts most commonly interacted with operations in Iowa, and around one-sixth of experts most commonly interacted with operations in Illinois, with the remaining states including Ohio, Minnesota, Texas, Nebraska, Indiana, Oklahoma, 
Citation: Wu Q, Schulz LL, Tonsor GT, Smith JM (2017) Expert Views on Effectiveness, Feasibility, and Implementation of Biosecurity Measures for Mitigating Tier 1 Disease Risks in the U.S. Swine, Beef Cattle, and Dairy Industries. J Vet Sci Technol 8:1735. doi: 7579.1000435

\begin{tabular}{|c|c|c|c|}
\hline \multirow[t]{2}{*}{ Respondent Characteristics } & Swine & Beef cattle & Dairy \\
\hline & $\%$ & $\%$ & $\%$ \\
\hline \multicolumn{4}{|c|}{$\begin{array}{l}\text { Level of knowledge regarding animal disease development, spread, } \\
\text { mitigation, or risk }\end{array}$} \\
\hline No expertise & 0 & 0 & 0 \\
\hline Below average expertise & 0 & 0 & 5 \\
\hline Average expertise & 33 & 21 & 27 \\
\hline Above average expertise & 33 & 42 & 38 \\
\hline Substantial expertise & 33 & 37 & 30 \\
\hline \multicolumn{4}{|c|}{ Discipline or area of expertise and focus } \\
\hline Animal Science & 6 & 5 & 3 \\
\hline Economics & 0 & 0 & 5 \\
\hline Epidemiology & 6 & 11 & 5 \\
\hline Veterinary medicine & 85 & 79 & 73 \\
\hline Other & 3 & 5 & 14 \\
\hline \multicolumn{4}{|l|}{ Current employer } \\
\hline University/academia & 12 & 32 & 14 \\
\hline Government/public sector & 18 & 37 & 38 \\
\hline Industry & 64 & 21 & 22 \\
\hline Other & 6 & 11 & 27 \\
\hline \multicolumn{4}{|l|}{ Contributions } \\
\hline $\begin{array}{l}\text { Presentations (at a producer } \\
\text { meeting) }\end{array}$ & 94 & 87 & 89 \\
\hline Non peer-reviewed publications & 85 & 74 & 73 \\
\hline Peer-reviewed publications & 55 & 50 & 43 \\
\hline $\begin{array}{l}\text { Do you personally own or manage } \\
\text { an operation }\end{array}$ & 12 & 47 & 11 \\
\hline Number of observations & 33 & 38 & 37 \\
\hline
\end{tabular}

Table 1: Select survey respondent demographics.
Kansas, North Carolina, and Georgia. These states represent $48 \%$ of U.S. swine operations and $84 \%$ of the U.S. hog inventory. The states that beef cattle experts most commonly interacted with were Kansas, Nebraska, Mississippi, Missouri, Texas, Iowa, Kentucky, Alabama, Illinois, Arkansas, Colorado, Michigan, Ohio, Georgia, Washington, California, Oregon, North Dakota, Tennessee, Wyoming, and Pennsylvania. These states represent $67 \%$ of U.S. beef cow operations, $64 \%$ of the U.S. beef cow inventory, $61 \%$ of U.S. cattle on feed operations, and $83 \%$ of the U.S. cattle on feed inventory. Most of the dairy experts most commonly interacted with operations in Wisconsin, with a second tier including Texas, Washington, California, Ohio, New York, Minnesota, Pennsylvania, and a third tier including Vermont, Florida, Michigan, Virginia, New Mexico, Maryland, Missouri, Indiana, Arizona, Idaho, and New Jersey. These states represent $77 \%$ of U.S. dairy cow operations and $84 \%$ of the U.S. dairy cow inventory [24].

\section{Assessment of routes of disease transmission}

Rating of effectiveness, feasibility, and implementation of biosecurity measures targeting specific disease transmission routes are summarized in Table 2 for the swine, beef cattle, and dairy industries, respectively.

Biosecurity targeting four disease transmission routes-direct animal-to-animal contact, semen, people, and vehicles and other fomites-was identified as the most effective and feasible for the swine, beef cattle, and dairy industries. Biosecurity targeting manure and bedding was not far behind for all three industries. However, the swine industry, but not the beef cattle or dairy industries, indicated effectiveness and feasibility of controlling wild carrying agents as

\begin{tabular}{|c|c|c|c|c|c|c|}
\hline \multirow[t]{2}{*}{ Routes of disease transmission } & \multirow{2}{*}{$\begin{array}{l}\text { Highly effective } \\
\text { highly feasible \% }\end{array}$} & \multirow{2}{*}{$\begin{array}{c}\text { Highly effective } \\
\text { highly infeasible \% }\end{array}$} & \multirow{2}{*}{$\begin{array}{l}\text { Highly ineffective } \\
\text { highly feasible \% }\end{array}$} & \multirow{2}{*}{$\begin{array}{l}\text { Highly ineffective } \\
\text { highly infeasible \% }\end{array}$} & \multicolumn{2}{|c|}{ Implementation $^{1}$} \\
\hline & & & & & Mean & Std. dev. \\
\hline \multicolumn{7}{|l|}{ Swine Industry $(\mathrm{N}=33)$} \\
\hline Direct animal-to-animal contact & 64 & 3 & 0 & 0 & 3.09 & 0.84 \\
\hline Semen & 58 & 0 & 3 & 0 & 3.36 & 0.90 \\
\hline Airborne transmission & 9 & 3 & 0 & 12 & 1.67 & 0.69 \\
\hline People & 55 & 0 & 0 & 0 & 3.00 & 0.75 \\
\hline Vehicles and other fomites & 58 & 3 & 0 & 0 & 2.67 & 0.69 \\
\hline Feed and drinking-water & 27 & 3 & 0 & 0 & 2.24 & 0.94 \\
\hline Manure and bedding & 33 & 0 & 6 & 0 & 2.52 & 0.83 \\
\hline Wild carrying agents & 33 & 0 & 3 & 3 & 2.52 & 0.87 \\
\hline Arthropods & 9 & 0 & 3 & 15 & 1.91 & 0.81 \\
\hline \multicolumn{7}{|l|}{ Beef Cattle Industry ( $\mathrm{N}=\mathbf{3 8}$ ) } \\
\hline Direct animal-to-animal contact & 36 & 8 & 0 & 0 & 1.97 & 0.89 \\
\hline Semen & 46 & 3 & 8 & 0 & 2.79 & 1.02 \\
\hline Airborne transmission & 5 & 13 & 0 & 0 & 1.42 & 0.72 \\
\hline People & 41 & 0 & 0 & 0 & 1.90 & 0.76 \\
\hline Vehicles and other fomites & 46 & 3 & 0 & 0 & 1.74 & 0.83 \\
\hline Feed and drinking-water & 15 & 0 & 5 & 3 & 1.87 & 0.88 \\
\hline Manure and bedding & 33 & 3 & 3 & 3 & 1.82 & 0.77 \\
\hline Wild carrying agents & 0 & 18 & 0 & 18 & 1.26 & 0.45 \\
\hline Arthropods & 5 & 8 & 0 & 18 & 1.76 & 0.85 \\
\hline \multicolumn{7}{|l|}{ Dairy Industry $(\mathrm{N}=37)$} \\
\hline Direct animal-to-animal contact & 37 & 5 & 0 & 3 & 1.92 & 0.98 \\
\hline Semen & 42 & 0 & 11 & 11 & 2.73 & 1.15 \\
\hline Airborne transmission & 5 & 8 & 0 & 37 & 1.30 & 0.62 \\
\hline People & 45 & 0 & 3 & 3 & 1.68 & 0.75 \\
\hline Vehicles and other fomites & 39 & 3 & 0 & 0 & 1.73 & 0.84 \\
\hline Feed and drinking-water & 29 & 0 & 0 & 5 & 1.81 & 0.85 \\
\hline Manure and bedding & 34 & 0 & 0 & 11 & 1.89 & 0.84 \\
\hline Wild carrying agents & 0 & 11 & 3 & 16 & 1.68 & 0.75 \\
\hline Arthropods & 11 & 8 & 0 & 18 & 1.73 & 0.87 \\
\hline
\end{tabular}

${ }^{1}$ The survey instrument collected information on current implementation using categorical variables $1=25 \%$ or less, $2=26-50 \%, 3=51-75 \%, 4=76 \%$ or more

Table 2: Summary of effectiveness, feasibility, and implementation of biosecurity measures targeting disease transmission route in the swine, beef cattle, and dairy Industry. 
Citation: Wu Q, Schulz LL, Tonsor GT, Smith JM (2017) Expert Views on Effectiveness, Feasibility, and Implementation of Biosecurity Measures for Mitigating Tier 1 Disease Risks in the U.S. Swine, Beef Cattle, and Dairy Industries. J Vet Sci Technol 8:1735. doi: 7579.1000435

high as managing manure and bedding. Efforts targeting airborne and arthropod transmission were ranked low for effectiveness and feasibility across all three industries.

In terms of estimated current implementation, biosecurity measures targeting semen were highest followed by those targeting direct animal-to-animal contact as a route of disease transmission across the swine, beef cattle, and dairy industries. The lowest level of estimated implementation was against wild carrying agents in the beef cattle industry and against airborne transmission in the swine and dairy industries. Estimated current implementation and differences between industries are displayed in Table 3 .

\section{Assessment of biosecurity measures}

The estimated implementation of specific biosecurity measures are shown for the swine, beef cattle, and dairy industries (Tables 4, 5 and 6 respectively) along with the percentage of experts ranking any measure at the extremes for effectiveness and feasibility. In the swine industry, the biosecurity measure of all-in and all-out production had the highest estimated current implementation; whereas protocols for pathogen reduction to reduce environmental viral load had the lowest estimated implementation. In the beef cattle industry, performing daily observations by producer/employees had the highest estimated

\begin{tabular}{|c|c|c|c|c|c|c|c|c|c|c|c|c|}
\hline \multirow[t]{3}{*}{ Route of disease transmission } & \multirow{2}{*}{\multicolumn{2}{|c|}{$\begin{array}{c}\text { Swine } \\
(N=33)\end{array}$}} & \multirow{2}{*}{\multicolumn{2}{|c|}{$\begin{array}{c}\text { Beef } \\
(\mathbf{N}=\mathbf{3 8})\end{array}$}} & \multirow{2}{*}{\multicolumn{2}{|c|}{$\begin{array}{c}\text { Dairy } \\
(\mathbf{N}=\mathbf{3 7})\end{array}$}} & \multirow{2}{*}{\multicolumn{2}{|c|}{ Swine-Beef }} & \multirow{2}{*}{\multicolumn{2}{|c|}{ Swine-Dairy }} & \multirow{2}{*}{\multicolumn{2}{|c|}{ Beef-Dairy }} \\
\hline & & & & & & & & & & & & \\
\hline & Mean & Std. dev. & Mean & Std. dev. & Mean & Std. dev. & t-stat & p-value & t-stat & p-value & t-stat & p-value \\
\hline Direct animal-to-animal contact & 3.09 & 0.84 & 1.97 & 0.88 & 1.92 & 0.98 & 5.42 & 0.00 & 5.32 & 0.00 & 0.25 & 0.80 \\
\hline Semen & 3.36 & 0.90 & 2.79 & 1.02 & 2.73 & 1.15 & 2.51 & 0.01 & 2.56 & 0.01 & 0.24 & 0.81 \\
\hline Airborne transmission & 1.67 & 0.69 & 1.42 & 0.72 & 1.30 & 0.62 & 1.46 & 0.15 & 2.36 & 0.02 & 0.80 & 0.43 \\
\hline People & 3.00 & 0.75 & 1.89 & 0.76 & 1.68 & 0.75 & 6.13 & 0.00 & 7.39 & 0.00 & 1.26 & 0.21 \\
\hline Vehicles and other fomites & 2.67 & 0.69 & 1.74 & 0.83 & 1.73 & 0.84 & 5.09 & 0.00 & 5.06 & 0.00 & 0.04 & 0.97 \\
\hline Feed and drinking-water & 2.24 & 0.94 & 1.87 & 0.88 & 1.81 & 0.84 & 1.74 & 0.09 & 2.03 & 0.05 & 0.29 & 0.77 \\
\hline Manure and bedding & 2.52 & 0.83 & 1.82 & 0.77 & 1.89 & 0.84 & 3.68 & 0.00 & 3.10 & 0.00 & -0.41 & 0.68 \\
\hline Wild carrying agents & 2.52 & 0.87 & 1.26 & 0.45 & 1.68 & 0.75 & 7.77 & 0.00 & 4.34 & 0.00 & -2.91 & 0.00 \\
\hline Arthropods & 1.91 & 0.80 & 1.76 & 0.85 & 1.73 & 0.87 & 0.74 & 0.46 & 0.89 & 0.38 & 0.17 & 0.87 \\
\hline
\end{tabular}

${ }^{1}$ The survey instrument collected information on current national implementation using categorical variables $1=25 \%$ or less, $2=26-50 \%, 3=51-75 \%, 4=76 \%$ or more.

Table 3: Differences of swine, beef cattle, and dairy industry experts' assessment of implementation of biosecurity measures targeting disease transmission routes ${ }^{1}$.

Biosecurity measure

\begin{tabular}{|c|c|c|c|c|c|c|c|}
\hline \multirow[t]{2}{*}{ Biosecurity measure } & \multirow[b]{2}{*}{ Obs } & \multirow{2}{*}{$\begin{array}{c}\text { Highly } \\
\text { effective } \\
\text { highly } \\
\text { feasible }\end{array}$} & \multirow{2}{*}{$\begin{array}{c}\begin{array}{c}\text { Highly } \\
\text { effective } \\
\text { highly }\end{array} \\
\text { infeasible }\end{array}$} & \multirow{2}{*}{\begin{tabular}{|c}
$\begin{array}{c}\text { Highly } \\
\text { ineffective } \\
\text { highly } \\
\text { feasible }\end{array}$ \\
$\%$
\end{tabular}} & \multirow{2}{*}{\begin{tabular}{|c|}
$\begin{array}{c}\text { Highly } \\
\text { ineffective } \\
\text { highly } \\
\text { infeasible }\end{array}$ \\
$\%$
\end{tabular}} & \multicolumn{2}{|c|}{ Implementation ${ }^{1}$} \\
\hline & & & & & & Mean & Std. dev. \\
\hline $\begin{array}{l}\text { A communication/education plan is in place to inform visitors and service providers of } \\
\text { disease status and biosecurity requirements }\end{array}$ & 8 & 63 & 0 & 13 & 0 & 3.13 & 0.83 \\
\hline Line of separation is in place for all visitors and service providers entering premises & 7 & 57 & 0 & 0 & 0 & 2.86 & 0.38 \\
\hline $\begin{array}{l}\text { Protocols have been developed and implemented to contain and/or exclude the targeted } \\
\text { virus within the affected premises }\end{array}$ & 7 & 43 & 0 & 0 & 0 & 2.43 & 0.79 \\
\hline $\begin{array}{l}\text { A communication/education plan is in place to inform employees of disease status and } \\
\text { biosecurity requirements }\end{array}$ & 10 & 30 & 0 & 0 & 0 & 2.60 & 0.70 \\
\hline Line of separation is in place for all employees entering premises & 8 & 50 & 0 & 0 & 0 & 2.88 & 0.64 \\
\hline Protocols for monitoring employee biosecurity compliance have been developed & 13 & 38 & 0 & 0 & 0 & 2.46 & 0.88 \\
\hline Timely visits by veterinarian(s) & 7 & 29 & 0 & 0 & 0 & 3.14 & 0.38 \\
\hline Daily observations by producer/employees & 9 & 22 & 0 & 0 & 0 & 3.00 & 0.87 \\
\hline Monitoring of production records for health status changes & 14 & 38 & 0 & 8 & 0 & 3.00 & 0.71 \\
\hline $\begin{array}{l}\text { Protocols: have been developed and implemented pertaining to transport biosecurity to } \\
\text { contain or exclude the targeted virus within the affected premises }\end{array}$ & 8 & 38 & 0 & 0 & 0 & 2.25 & 0.89 \\
\hline $\begin{array}{l}\text { Protocols have been developed for cleaning and/or disinfecting vehicles for certain } \\
\text { animal movements (required for verification of biosecurity payments) }\end{array}$ & 8 & 25 & 0 & 0 & 0 & 2.38 & 0.74 \\
\hline Line of separation is in place for all animals entering and leaving premises & 5 & 80 & 0 & 0 & 0 & 3.00 & 1.00 \\
\hline $\begin{array}{l}\text { Protocols for loading/unloading animals that attempt to minimize virus introduction have } \\
\text { been developed and implemented }\end{array}$ & 9 & 33 & 0 & 11 & 0 & 2.89 & 0.78 \\
\hline $\begin{array}{l}\text { Protocols for pathogen reduction have been developed and implemented to reduce } \\
\text { environmental viral load }\end{array}$ & 6 & 33 & 0 & 0 & 17 & 2.00 & 0.89 \\
\hline Use of an effective disinfectant (required for verification of biosecurity payments) & 12 & 58 & 0 & 0 & 0 & 2.67 & 0.65 \\
\hline Follow appropriate downtimes after cleaning and disinfection & 11 & 55 & 0 & 0 & 0 & 2.64 & 0.81 \\
\hline Where possible, use all-in and all-out production practices & 14 & 43 & 0 & 0 & 0 & 3.29 & 0.73 \\
\hline $\begin{array}{l}\text { Protocols have been developed and implemented to establish stabilization and } \\
\text { monitoring for the affected premises (monitoring may include submission of samples to } \\
\text { a diagnostic laboratory for testing) }\end{array}$ & 6 & 50 & 0 & 0 & 0 & 2.33 & 0.52 \\
\hline Movements of animals on and off the premises are routinely recorded & 4 & 75 & 0 & 0 & 0 & 3.25 & 0.50 \\
\hline
\end{tabular}

${ }^{1}$ The survey instrument collected information on current implementation using categorical variables $1=25 \%$ or less, $2=26-50 \%, 3=51-75 \%, 4=76 \%$ or more. Table 4: Summary of effectiveness, feasibility, and implementation of biosecurity measures in the swine industry. 
Citation: Wu Q, Schulz LL, Tonsor GT, Smith JM (2017) Expert Views on Effectiveness, Feasibility, and Implementation of Biosecurity Measures for Mitigating Tier 1 Disease Risks in the U.S. Swine, Beef Cattle, and Dairy Industries. J Vet Sci Technol 8:1735. doi: 7579.1000435

Page 5 of 7

\section{Biosecurity measure}

A communication/education plan is in place to inform visitors and service providers of disease status and biosecurity requirements

Line of separation is in place for all visitors and service providers entering premises Protocols have been developed and implemented to contain and/or exclude the targeted virus within the affected premises

A communication/education plan is in place to inform employees of disease status and biosecurity requirements

Line of separation is in place for all employees entering premises

Protocols for monitoring employee biosecurity compliance have been developed

Timely visits by veterinarian(s)

Daily observations by producer/employees

Monitoring of production records for health status changes

Protocols: have been developed and implemented pertaining to transport biosecurity to contain or exclude the targeted virus within the affected premises

Protocols have been developed for cleaning and/or disinfecting vehicles for certain animal movements (required for verification of biosecurity payments)

Line of separation is in place for all animals entering and leaving premises

Protocols for loading/unloading animals that attempt to minimize virus introduction have been developed and implemented

Protocols for pathogen reduction have been developed and implemented to reduce environmental viral load

Use of an effective disinfectant (required for verification of biosecurity payments)

Follow appropriate downtimes after cleaning and disinfection

Where possible, use all-in and all-out production practices

Protocols have been developed and implemented to establish stabilization and

monitoring for the affected premises (monitoring may include submission of samples to

a diagnostic laboratory for testing)

Movements of animals on and off the premises are routinely recorded

\begin{tabular}{|c|c|c|c|c|c|c|}
\hline & & & & Highly & Impler & tation ${ }^{1}$ \\
\hline Obs & $\%$ & $\%$ & $\%$ & $\%$ & Mean & Std. dev. \\
\hline 9 & 33 & 0 & 0 & 0 & 1.78 & 0.67 \\
\hline 10 & 80 & 0 & 0 & 0 & 1.50 & 0.85 \\
\hline 10 & 55 & 0 & 0 & 10 & 1.70 & 0.67 \\
\hline 11 & 55 & 0 & 0 & 0 & 1.45 & 0.69 \\
\hline 8 & 63 & 13 & 0 & 0 & 1.38 & 0.52 \\
\hline 8 & 0 & 0 & 0 & 0 & 1.75 & 0.46 \\
\hline 16 & 25 & 0 & 0 & 0 & 1.94 & 1.00 \\
\hline 10 & 40 & 0 & 0 & 0 & 2.40 & 0.97 \\
\hline 15 & 40 & 0 & 13 & 7 & 1.67 & 0.82 \\
\hline 8 & 38 & 0 & 0 & 0 & 1.63 & 1.06 \\
\hline 8 & 50 & 13 & 0 & 0 & 1.50 & 0.76 \\
\hline 10 & 50 & 10 & 0 & 0 & 1.30 & 0.67 \\
\hline 12 & 42 & 0 & 0 & 0 & 1.67 & 0.78 \\
\hline 8 & 50 & 0 & 0 & 0 & 1.13 & 0.35 \\
\hline 6 & 67 & 17 & 0 & 0 & 1.67 & 0.82 \\
\hline 13 & 46 & 0 & 0 & 0 & 1.69 & 0.63 \\
\hline 7 & 29 & 43 & 0 & 14 & 1.43 & 0.79 \\
\hline 8 & 88 & 0 & 0 & 0 & 2.00 & 1.07 \\
\hline 13 & 15 & 0 & 8 & 0 & 2.15 & 0.90 \\
\hline
\end{tabular}

${ }^{1}$ The survey instrument collected information on current implementation using categorical variables $1=25 \%$ or less, $2=26-50 \%, 3=51-75 \%, 4=76 \%$ or more.

Table 5: Summary of effectiveness, feasibility, and implementation of biosecurity measures in the beef cattle industry.

current implementation. Similar to the swine industry, protocols for pathogen reduction to reduce environmental viral load had the lowest estimated implementation in the beef cattle industry. In the dairy industry, monitoring production records for health status changes and timely visits by veterinarian(s) had the highest estimated current implementation; whereas line of separation in place for all employees entering premises had the lowest estimated current implementation.

Swine experts considered the biosecurity measure of separation line for all animals entering and leaving premises as most effective and feasible ( $80 \%$ of experts identified as both highly effective and highly feasible) and protocols for pathogen reduction to reduce environmental viral load as the least effective and feasible (17\% of experts identified as both highly ineffective and highly infeasible). Beef cattle experts identified protocols to establish stabilization and monitoring for the affected premises as most effective and feasible (88\%); whereas the dairy cattle experts identified daily observations by producer/employees as most effective and feasible (71\%). All-in and all-out production was rated the least effective and feasible by both beef cattle (14\%) and dairy (8\%) experts.

\section{Discussion}

\section{Respondents}

The low response rate necessitates caution when interpreting results. It is unknown whether asking these experts to respond based on number of operations versus number of animals would have affected the results. Also, industry experts were asked for global assessments even if their assessment would have differed by specific production segment (i.e., farrowing versus finishing or cow-calf versus feedlot). However, the number of responses from experts with beef cattle, dairy, or swine experience were fairly even and geographically representative of the areas of highest concentrations of production. Future producer surveys, informed by these results, will provide a more complete picture of the implementation of biosecurity practices on these types of livestock farms.

\section{Biosecurity and disease transmission route}

Across industries, the swine industry had higher estimated implementation of biosecurity against almost all disease transmission routes. This reflects the fact that the vast majority of commercially produced pigs do not have outside access, and therefore, are raised in more controlled environments than most cattle. Biosecurity against disease transmission by semen and direct animal-to-animal contact were consistently ranked highest in terms of implementation by experts from all three industries. Biosecurity against these routes of transmission was also considered effective and feasible. The implementation of biosecurity against two routes of disease transmission, airborne and arthropod-borne, was estimated to be less than $25 \%$ nationally by the swine industry and was not different from the implementation estimate for the beef industry (and beef was not different from dairy). In general, estimated current implementation of biosecurity measures targeting disease transmission routes was found to be more strongly correlated with feasibility than with effectiveness in the disease transmission routes across the three industries (data not 
Citation: Wu Q, Schulz LL, Tonsor GT, Smith JM (2017) Expert Views on Effectiveness, Feasibility, and Implementation of Biosecurity Measures for Mitigating Tier 1 Disease Risks in the U.S. Swine, Beef Cattle, and Dairy Industries. J Vet Sci Technol 8:1735. doi: 7579.1000435

Page 6 of 7

\section{Biosecurity measure}

\begin{tabular}{|c|c|c|c|c|c|c|c|}
\hline \multirow[t]{2}{*}{ Biosecurity measure } & \multirow{2}{*}{\multicolumn{2}{|c|}{\begin{tabular}{|c|c|} 
& $\begin{array}{c}\text { Highly } \\
\text { effective } \\
\text { highly } \\
\text { feasible }\end{array}$ \\
Obs & $\%$
\end{tabular}}} & \multirow{2}{*}{$\begin{array}{c}\begin{array}{c}\text { Highly } \\
\text { effective } \\
\text { highly }\end{array} \\
\text { infeasible }\end{array}$} & \multirow{2}{*}{\begin{tabular}{|c|}
$\begin{array}{c}\text { Highly } \\
\text { ineffective } \\
\text { highly } \\
\text { feasible }\end{array}$ \\
$\%$
\end{tabular}} & \multirow{2}{*}{$\begin{array}{c}\begin{array}{c}\text { Highly } \\
\text { ineffective } \\
\text { highly } \\
\text { infeasible }\end{array} \\
\% \\
\end{array}$} & \multicolumn{2}{|c|}{ Implementation ${ }^{1}$} \\
\hline & & & & & & Mean & Std. dev. \\
\hline $\begin{array}{l}\text { A communication/education plan is in place to inform visitors and service providers of } \\
\text { disease status and biosecurity requirements }\end{array}$ & 9 & 11 & 0 & 22 & 0 & 1.89 & 0.93 \\
\hline Line of separation is in place for all visitors and service providers entering premises & 11 & 27 & 9 & 9 & 0 & 1.18 & 0.40 \\
\hline $\begin{array}{l}\text { Protocols have been developed and implemented to contain and/or exclude the } \\
\text { targeted virus within the affected premises }\end{array}$ & 8 & 13 & 0 & 0 & 0 & 1.25 & 0.46 \\
\hline $\begin{array}{l}\text { A communication/education plan is in place to inform employees of disease status and } \\
\text { biosecurity requirements }\end{array}$ & 7 & 57 & 0 & 14 & 0 & 1.71 & 0.95 \\
\hline Line of separation is in place for all employees entering premises & 9 & 11 & 0 & 0 & 0 & 1.11 & 0.33 \\
\hline Protocols for monitoring employee biosecurity compliance have been developed & 6 & 50 & 0 & 0 & 0 & 1.33 & 0.52 \\
\hline Timely visits by veterinarian(s) & 9 & 33 & 0 & 0 & 0 & 2.22 & 0.44 \\
\hline Daily observations by producer/employees & 7 & 71 & 0 & 0 & 0 & 2.14 & 0.90 \\
\hline Monitoring of production records for health status changes & 7 & 57 & 0 & 0 & 0 & 2.29 & 1.11 \\
\hline $\begin{array}{l}\text { Protocols: have been developed and implemented pertaining to transport biosecurity to } \\
\text { contain or exclude the targeted virus within the affected premises }\end{array}$ & 7 & 43 & 0 & 0 & 0 & 1.57 & 0.79 \\
\hline $\begin{array}{l}\text { Protocols have been developed for cleaning and/or disinfecting vehicles for certain } \\
\text { animal movements (required for verification of biosecurity payments) }\end{array}$ & 9 & 44 & 0 & 0 & 0 & 1.89 & 1.05 \\
\hline Line of separation is in place for all animals entering and leaving premises & 8 & 50 & 0 & 13 & 0 & 1.38 & 0.74 \\
\hline $\begin{array}{l}\text { Protocols for loading/unloading animals that attempt to minimize virus introduction have } \\
\text { been developed and implemented }\end{array}$ & 10 & 20 & 0 & 0 & 0 & 1.60 & 0.70 \\
\hline $\begin{array}{l}\text { Protocols for pathogen reduction have been developed and implemented to reduce } \\
\text { environmental viral load }\end{array}$ & 21 & 38 & 5 & 0 & 0 & 1.62 & 0.80 \\
\hline Use of an effective disinfectant (required for verification of biosecurity payments) & 11 & 18 & 0 & 0 & 0 & 1.36 & 0.50 \\
\hline Follow appropriate downtimes after cleaning and disinfection & 14 & 43 & 0 & 0 & 0 & 2.07 & 1.00 \\
\hline Where possible, use all-in and all-out production practices & 12 & 8 & 42 & 0 & 8 & 1.25 & 0.62 \\
\hline $\begin{array}{l}\text { Protocols have been developed and implemented to establish stabilization and } \\
\text { monitoring for the affected premises (monitoring may include submission of samples to } \\
\text { a diagnostic laboratory for testing) }\end{array}$ & 10 & 60 & 0 & 0 & 0 & 1.60 & 0.84 \\
\hline Movements of animals on and off the premises are routinely recorded & 10 & 50 & 0 & 0 & 0 & 2.10 & 0.99 \\
\hline
\end{tabular}

${ }^{1}$ The survey instrument collected information on current implementation using categorical variables $1=25 \%$ or less, $2=26-50 \%, 3=51-75 \%, 4=76 \%$ or more.

Table 6: Summary of effectiveness, feasibility, and implementation of biosecurity measures in the dairy industry.

shown). This is not surprising as producer implementation decisions are likely to reflect privately absorbed costs and perhaps only partially internalize the broader, social values of more effective biosecurity measures.

\section{Biosecurity measures}

Swine industry experts estimated that over $50 \%$ of the industry was implementing all-in all-out production (where possible), recording movements of animals, accessing veterinary services in a timely manner, communicating biosecurity requirements with visitors and service personnel, monitoring production records for changes in health status, observing animals daily, and maintaining a line of separation for animals entering and leaving the premises. Of these practices, maintaining a line of separation for animals entering and leaving, was ranked as being both highly effective and highly feasible by the greatest number of experts (80\%). However, maintaining a line of separation for all visitors and service providers and for all employees was ranked as highly effective and highly feasible by fewer experts (57\% and $50 \%$, respectively) and is estimated to be implemented by fewer than $50 \%$ of the industry. Establishing a premises line of separation for people and animals is a key component of Secure Food Supply guidance to support continuity of operations in the event of a foreign animal disease outbreak (http://www.securepork.org/plan-components.php). As such it is an important biosecurity measure to mitigate a Tier 1 disease risk.

Another key component of Secure Food Supply guidance is observation and reporting of animal health status. Accessing veterinary services in a timely manner, monitoring production records, and observing animals daily are all implemented widely by the industry, despite being ranked highly effective and highly feasible by fewer than $50 \%$ of expert respondents. Managed movements of animals would be part of a foreign animal disease response. Recording of movements is important for tracing disease (forward or back) and has been implemented by more than $50 \%$ of the industry.

All-in all-out production is used by over $70 \%$ of nursery pig [25] and over $80 \%$ of feeder-to-finish farms [26] and has been shown since the early 1990s to improve health and performance [27], primarily by facilitating the control of respiratory diseases and reducing variability within lots of hogs marketed. Premises with all-in all-out production were able to implement protocols to eliminate porcine epidemic diarrhea virus from herds (personal communication). The integration of movement between premises specializing in different production phases requires pre-planning to address movement management in the event of a foreign animal disease outbreak.

Interestingly, the list of biosecurity measures, informed by the literature, from which experts were asked to evaluate a subset does not include any practices designed to minimize disease transmission risk by means of airborne or arthropod-borne spread. Efforts to minimize feed and water contamination do not appear on this list either. Manure management as a measure to prevent feed and water contamination and vector control in general do commonly appear in biosecurity recommendations in the United States [28]. 
Citation: Wu Q, Schulz LL, Tonsor GT, Smith JM (2017) Expert Views on Effectiveness, Feasibility, and Implementation of Biosecurity Measures for Mitigating Tier 1 Disease Risks in the U.S. Swine, Beef Cattle, and Dairy Industries. J Vet Sci Technol 8:1735. doi: 7579.1000435

\section{Conclusion}

Experts report differences in effectiveness, feasibility, and current implementation of biosecurity measures targeting disease transmission routes and recommended biosecurity measures among swine, beef, and dairy industries. With this information, a targeted set of disease transmission routes and biosecurity measures can be examined that would allow for a more in-depth and refined study, enhancing the power of future studies, and improving the ability to formulate recommendations. All biosecurity measures come with a cost and ineffective and infeasible methods should be avoided. Likewise, transmission routes that impose the greatest risk should be the focus, rather than low-risk transmission routes.

The information and infrastructure needed to achieve adequate biosecurity can vary significantly by industries. Variations in the management and marketing structure of each livestock industry, including size and reliance on extensive movement of animals, can complicate progress towards achieving sufficient biosecurity. Prioritization of the most effective and feasible biosecurity measures will ensure resources are applied where biosecurity advances are of the highest importance and that will offer the greatest return on investment.

\section{Acknowledgements}

This material is based upon work that is supported by the National Institute of Food and Agriculture, U.S. Department of Agriculture, under award number 201569004-23273

\section{References}

1. Roth JA, Spickler AR (2014) FMD vaccine surge capacity for emergency use in the United States. Vet Microbiol and Prev Med Rep, Paper 8. Accessed on: 8 August 16.

2. Food and Agriculture Organization of the United Nations/World Organisation for Animal Health/World Bank (2010) Good practices for biosecurity in the pig sector - Issues and options in developing and transition countries. FAO Animal Production and Health Paper No. 169. Rome, FAO

3. Lewerin SS, Österberg J, Alenius S, Elvander M, Fellström C, et al. (2015) Risk assessment as a tool for improving external biosecurity at farm level. BMC Vet Res. 11: 171-181.

4. Sutherst RW (2001) The vulnerability of animal and human health to parasites under global change. Int J Parasitol. 31: 933-948

5. Dee S, Clement T, Schelkopf A, Nerem J, Knudsen D, et al. (2014) An evaluation of contaminated complete feed as a vehicle for porcine epidemic diarrhea virus infection of naïve pigs following consumption via natural feeding behavior: proof of concept. BMC Vet Res. 10: 176

6. US Department of Agriculture Animal and Plant Health Inspection Service Veterinary Services (2010) Beef 2007-08, Part IV reference of beef cow-calf management practices in the United States. February 2010. Accessed on: 29 October 2016.

7. Smith WA, Strand J (2008) Social marketing behavior: A practical resource for social change professionals. Academy for Educational Development Washington DC, USA.

8. Gunn GJ, Heffernan C, Hall M, McLeod A, Hovi M (2008) Measuring and comparing constraints to improved biosecurity amongst gb farmers, veterinarians and the auxiliary industries. Prev Vet Med. 84: 310-323.

9. Heffernan C, Nielsen L, Thomson K, Gunn G (2008) An exploration of the drivers to bio-security collective action among a sample of UK cattle and sheep farmers. Prev Vet Med. 87: 358-372.

10. Delgado AH, Norby B, Scott HM, Dean W, McIntosh WA, et al. (2014) Distribution of cow-calf producers' beliefs about reporting cattle with clinical signs of footand-mouth disease to a veterinarian before or during a hypothetical outbreak. Prev Vet Med. 117: 505-517.

11. Delgado AH, Norby B, Scott HM, Dean W, Mclntosh WA, et al. (2014) Distribution of cow-calf producers' beliefs regarding gathering and holding their cattle and observing animal movement restrictions during an outbreak of footand-mouth disease. Prev Vet Med. 117: 518-532.

12. Nissen B, Krieter J (2003) Relative importance of risk factors concerning the introduction and spread of classical swine fever and foot-and-mouth disease in Germany. Arch Tierz. 46: 535-546.

13. Kuster K, Cousin ME, Jemmi T, Schüpbach-Regula G, Magouras I (2015) Expert opinion on the perceived effectiveness and importance of on-farm biosecurity measures for cattle and swine farms in Switzerland. Plos One. 10: e0144533.

14. Jochimsen AA (2015) The vulnerability of U.S. agriculture to foot and mouth disease. Master's thesis. Monterey, CA: Naval Postgraduate School.

15. Mankad A (2016) Psychological influences on biosecurity control and farmer decision-making. A review. Agron Sustain Dev. 36: 40.

16. Dewey C, Bottoms K, Carter N, Richardson K (2014) A qualitative study to identify potential biosecurity risks associated with feed delivery. J Swine Health Prod. 22: 232-243.

17. Hernández-Jover M, Gilmour J, Schembri N, Sysak T, Holyoake PK, et al. (2012) Use of stakeholder analysis to inform risk communication and extension strategies for improved biosecurity amongst small-scale pig producers. Prev Vet Med. 104: 258-270.

18. US Department of Agriculture Animal and Plant Health Inspection Service Veterinary Services (2014) Veterinary services herd/premises management plan requirements for Swine Enteric Coronavirus Disease (SECD) reported herds. Accessed on: 23 November 2015.

19. US Department of Agriculture Animal and Plant Health Inspection Service (2013) High-consequence foreign animal diseases and pests. Accessed on 12 November 2015.

20. Stata Corp LP (2016) Stata Statistical Software Release 14. StataCorp, LP College Station, TX, USA.

21. Cross P, Rigby D, Edwards-Jones G (2012) Eliciting expert opinion on the effectiveness and practicality of interventions in the farm and rural environment to reduce human exposure to escherichia coli O157. Epidemiol Infect. 140: 643-654.

22. Erdem S, Rigby D (2013) Investigating heterogeneity in the characterization of risks using best worst scaling. Risk Anal. 33: 1728-1748.

23. Tonsor GT, Schroeder TC, Mintert J (2014) Using expert knowledge to guide commodity promotion and research program investments: A US beef industry example. J Agribus. 32: 1.

24. US Department of Agriculture National Agricultural Statistics Service (2014) 2012 census of agriculture, United States summary and state data. May 2014 Accessed on: 5 September 2016.

25. US Department of Agriculture Animal and Plant Health Inspection Service Veterinary Services Centers for Epidemiology and Animal Health (2009) Nursery and grower/finisher management in swine 2000 and swine 2006. Accessed on: 16 December 2016.

26. McBride WD, Key N (2013) US Hog production from 1992 to 2009: Technology restructuring, and productivity growth, ERR-158. US Department of Agriculture, Economic Research Service. Accessed on: 16 December 2016.

27. Scheidt AB, Cline TR, Clark LK, Mayrose VB, Van Alstine WG, et al. (1995) The effect of all-in-all-out growing-finishing on the health of pigs. J Swine Health Prod. 3: 202-205.

28. Moore DA, Merryman ML, Hartman ML, Klingborg DJ (2008) Comparison of published recommendations regarding biosecurity practices for various production animal species and classes. J Amer Vet Med Assoc 233: 249-256. 